\title{
Presence of G84E Allelic Heterogeneity of the European Prostate Cancer SNP Mutation of HOX13B-G84E Associated with the European R-Haplogroup of Y-Chromosome and Absence of Gene Flow into Moroccans Patients
}

\author{
Ihsan Ali Mahasneh ${ }^{* \#}$, Moulay Mustapha Ennaji ${ }^{2}$, Berjas Abumsimir ${ }^{2}$, Yassine Kasmi² \\ ${ }^{1}$ Department of Biotechnology, Faculty of Science, University of Sharjah, Sharjah, UAE \\ ${ }^{2}$ Team of Virology, Oncology, and Medical Biotechnologies; Laboratory of Virology, Microbiology, Quality, and Biotechnologies/ \\ ETB; Faculty of Sciences and Techniques, Mohammedia, Hassan II University of Casablanca, Casablanca, Morocco \\ Email: \#imahasneh@sharjah.ac.ae,m.ennaji@yahoo.fr, berjas_last@yahoo.com, kasmi.yassin@gmail.com
}

How to cite this paper: Mahasneh, I.A., Ennaji, M.M., Abumsimir, B. and Kasmi, Y. (2021) Presence of G84E Allelic Heterogeneity of the European Prostate Cancer SNP Mutation of HOX13B-G84E Associated with the European R-Haplogroup of YChromosome and Absence of Gene Flow into Moroccans Patients. Journal of Biosciences and Medicines, 9, 50-61. https://doi.org/10.4236/jbm.2021.95006

Received: March 2, 2021

Accepted: May 23, 2021

Published: May 26, 2021

Copyright $\odot 2021$ by author(s) and Scientific Research Publishing Inc. This work is licensed under the Creative Commons Attribution International License (CC BY 4.0).

http://creativecommons.org/licenses/by/4.0/ (c) (i) Open Access

\begin{abstract}
SNP mutations in the HOXB13 gene associated with prostate cancer were determined in Moroccans prostate cancer patients (PCa). All PCa SNP mutations were new and belong to the SNP point-mutations located on the stop codon of HOXB13 exon 1 and 2 located in chromosome 17. The five mutations and their frequencies were as follows: rs1197613952 (12\%), rs1597934612 (4\%), rs1597933874 (4\%), rs1597933837 (4\%) and rs867793282 (4\%). The European HOXB13-G84E (rs138213197) PCa mutation was not detected among Moroccan patients. The Y-chromosome genealogical haplotypes of the Western European (R1b1b2-M2G9) and the Eastern European (R191a-M-17) were not observed in Moroccans PCa patients. The patients have their own haplotypes E1b1 and J with a frequency of 55 and 35\%, respectively. The results of the SNP mutations in the HOXB13, the absence of the HOXB13-G84E of the European in the Moroccans PCa patients, the absence of the European-lineage haplogroups (R1a1a-M17 and R1b1b2-M269) and the presence of E1b1b and J in Moroccans PCa patients would clearly indicate the absence of gene flow from European to Moroccans gene pool.
\end{abstract}

\section{Keywords}

Prostate Cancer, HOXB13, G84E, Allelic Heterogeneity, Y-Chromosome Haplogroups, European Genome, Moroccan Genome, Gene Flow 


\section{Introduction}

Recently, there has been a growing global research interest on profiling of the prostate cancer HOXB13 mutations, which is population-based and associated with the males' genealogy in different population [1]-[9]. Prostate cancer is the second most prevalent cancer in males, and the sixth cause of cancer-related deaths since it was first reported, and before the outset of the prevalence of the HOXB13-G84E mutation [10]. Furthermore, the germline HOXB13-G84E mutation has consistently been associated with prostate cancer (PCa) risk among European pedigree [7] [10] [11] [12] [13] [14]. More recently, in a wide-range population study that included results from the UK Biobank, it was documented that the G84E mutation was found in 1545 (0.34\%) subjects out of 460,224 participants of European pedigree [15]. On the contrary, further evidence to buttress and substantiate this assertion showed that the G84E mutation was not found among prostate cancer males of both African and Asian descent [12] [16]. For several years, our research outcomes on the Y-chromosome haplogroups of Arabs genealogical-lineages as determined by mutations of the Short Tandem Repeats (STRs) of the non-recombined region of the Y-chromosome showed that the epidemiology of cancers correlates with the genealogy and ethnicity of the population clusters [9] [17] [18] [19] [20] [21]. This has prompted the scientific question on whether the incidence of such ancestral-based mutation of prostate cancer in males is associated with or can be predicted by the gene flow in males' haplogroups and their genealogical-lineages vis-à-vis profiling of the Y-chromosome among different population. Consequently, we hypothesized the presence of allelic heterogeneity in prostate cancer mutation among Moroccan prostate cancer patients and European males. Our objectives were to determine and profile the gene flow of HOX13B-G84E and the Y-chromosome haplogroups (R1b1b2-M269 and R1a1a-M17) from European to Moroccan males taking into cognizance the fact that both populations are located on the very busy crossing route of human historical migration between the two ancient continents of Europe and Africa. Morocco was our preferred choice for this study, because it is located in the northwestern part of Africa, and has the closest proximity (with just $14 \mathrm{~km}$ away from Spain across the Gibraltar strait and the Atlantic Ocean to the west) for any possible reciprocal human migration to and from Europe. Additionally, Morocco represents a unique population cluster for testing our hypothesis, because it presented a vehicle to determine if there was a gene flow profile of the HOXB13-G84E mutation of prostate cancer associated with the European genealogy gene flow (if any) of the R1b1b2-M269 and R1a1a-M17 Y-chromosome haplogroups from Europe into Morocco.

\section{Materials and Methods}

\subsection{Genotyping of the Single Nucleotide Polymorphism (SNP) and PCR of HOXB13 Gene Cluster on Chromosome 17q21-22}

A total of 50 fresh prostate biopsies were collected from 50 men undergoing 
treatment for prostate cancer in Rabat City, Morocco. DNA processing and genotyping were conducted at the oncology and virology laboratory of the Faculty of Sciences and Techniques, Mohammedia, Morocco. DNA purification, sequencing and genotyping were performed at the innovation center facility of Fez, Morocco. DNA samples were collected from prostate cancer tissues. Sample size in the neighborhood of $\leq 25 \mathrm{mg}$ of minced tissue was placed in a sterile microcentrifuge tube for the purpose of centrifugation. DNA was separated from tissue samples employing PureLink Invitrogen genomic DNA Mini Kit, Thermo Fisher Scientific, USA, according to the manufacturer's protocol. DNA was quantified using the Nanodrop spectrophotometer. Samples with a DNA concentration of $20-50 \mathrm{ng} / \mu \mathrm{l}$ or above were selected for the polymerase chain reaction. The specific HOXB13 gene accession: (NM_006361.5) exons: one and two were targeted by polymerase chain reaction employing specific primers described elsewhere (23). A total volume of $15 \mu$ PCR containing genomic DNA (8 ng), $2 \times$ Taq PCR Master Mix Kit, Qiagen USA, $10 \mu \mathrm{mol}$ forward and reverse primers were employed to carry out the polymerase chain reaction. PCR products were then purified before genotyping of the HOXB13-G84E (rs138213197) SNP using forward and reverse primers as customized by the manufacturer on ABI Prism Genetic Analyzer 3130, and BigDye XTerminator ${ }^{\circledast}$ Purification Kit (Applied Biosystems, Foster City, CA). The resultant mutations were compared with RefSeq reference: (NM_006361.5). All the resultant novel mutations discovered in this study were submitted to ClinVar-NCBI Database and registered as clinical relevance variants, Condition ID type: MedGen, Condition ID value: C4722327 (Hereditary prostate cancer 1) under accession numbers: (SCV000993781 SCV000994542).

\subsection{Genotyping of the Y-Chromosome STRs and Haplogroup Lineages Prediction}

A total of 160 Moroccan blood samples were collected and subjected to DNA extraction procedures to determine the 17 loci: (DYS456, DYS389i, DYS390, DYS389ii, DYS458, DYS19, DYS385a, DYS385b, DYS393, DYS391, DYS439, DYS635, DYS392, TAGA H4, DYS437, DYS438, and DYS448). DNA was isolated according to the manufacturer's protocols employing the Wizard Genomic DNA Isolation Kit ${ }^{\circledR}$ (Promega, USA). The Bio-Rad SmartSpec Plus spectrophotometer was employed to determine the purity of DNA in compliance with the quality control check procedure. Electrophoresis was carried out using the Horizon 58 Agarose Gel Electrophoresis apparatus, which was required for photographing of the ethidium bromide stained gel. Gene amplification was conducted on the GeneAmp PCR System 9700 Thermo Cycler (Applied BioSystem) employing the Amp FISTR ${ }^{\circledR}$ Yfiler $^{\mathrm{TM}}$ PCR Amplification Kit (AmpFISTR Yfiler ${ }^{\mathrm{TM}}$ ) containing the allelic ladder. Thereafter, the STRs allelic genotyping were determined according to the manufacturer's protocols using the ABI Prism ${ }^{\circledR} 310$ Genetic Analyzer (Applied BioSystems) equipped with the GeneScan $500 \mathrm{Liz}$ Size Standard (LIZ-500) data collection software, version 3.1 and GeneMapper 
ID Software, version 4. The allelic data were produced by the Genetic Analyzer, which was collected by the Data Collection Software, version 3.1 and analyzed by the Gene Mapper ID software, version 4 (GeneScan analysis software and Genotyper software). Alleles were determined based on the recommendations of the DNA Commission of the International Society for Forensic Genetics. The Y-chromosome haplogroups of the genealogical-lineages were determined employing the Athey's Haplogroup Predictor, version 3.16.

\subsection{YHRD GeneBank Quality Assurance of Genotyping and Data Deposition}

In accordance with the request of the Y-STR Haplotype Reference Database $(Y H R D)$, we conducted the Quality Assurance Test in compliance with the YHRD guidelines. Our results of the Y-chromosome; were registered and deposited in the International Y-chromosome Haplotype Reference Database (YHRD) under the Accession Numbers YA003522 and YA003523 (http://www.yhrd.org/).

\section{Results}

The profile of the HOXB13 mutations and the coding sequence (CDS) changes among PCa Moroccan patients is presented in Table 1. The SNP genotyping revealed that all the PCa mutations identified among the Moroccan PCa patients were new and belong to the SNP point-nonsense mutation type, and are located on the stop codon of HOXB13 exon 1 and 2 of chromosome 17. The frequency of the most prevalent mutation among the Moroccan patients were rs1197613952 (12\%), rs1597934612 (4\%), rs1597933874 (4\%), rs1597933837 (4\%) and rs867793282 (4\%). The European HOXB13-G84E (rs138213197) PCa mutation was not identified among the Moroccan patients. The change in SNP of the HOXB13 mutations detected among PCa Moroccan patients were rs1197613952 (C > A), rs1597934612 (C > A), rs1597933874 (C > T), rs1597933837 (C > A) and rs867793282, $(\mathrm{G}>\mathrm{A})$. The change in the amino acids sequences and the resultant proteins formed by the HOXB13 SNP mutations detected among the Moroccan patients were p.Tyr87Ter, p.Tyr88Ter, p.Gln181Ter, p.Cys184Ter, and p.Trp195Ter; resulting from the change in SNP of $(C>A),(C>A),(C>T)$, $(C>A)$ and $(\mathrm{G}>\mathrm{A})$, respectively. The genomic landscape of the European genealogy of PCa mutation of HOXB13-G84E (rs138213197) and the Moroccan PCa mutations are presented in Figure 1. These mutations will cause disruption effect on among other genes at the 5' end of the 17q21-22 HOXB cluster of the Exon 1 and 2 and the three known functional domains (accession number NC_000017/11 and Prot ID Q92826). The range of the frequency rate of the HOXB13-G84E germline mutation in European countries is (0.5\% - 4.5\%) (Figure 2 ), which is totally absent in the Moroccans patents showing that there is no gene flow for the European HOXB13-G84E PCa mutations. Table 2 provides an analogy between the frequency of the $\mathrm{Y}$-chromosome genealogical haplogroups (Western European haplogroups R1b1b2-M269 and Eastern European haplogroups 
Table 1. Profile the SNP allelic heterogeneity of HOXB13 mutations in Moroccan prostate cancer in comparison with the European HOXB13 G84E (rs138213197) mutation.

\begin{tabular}{ccccc}
\hline Mutation location & CDS change & dbSNP number & $\begin{array}{c}\text { Amino acid/ } \\
\text { protein change }\end{array}$ & $\begin{array}{c}\text { Frequency (\%) } \\
\mathrm{N}=50\end{array}$ \\
\hline Chr17: 48728333 & c.261C $>$ A & rs1197613952 & p.Tyr87Ter & $(12 \%)$ \\
Chr17: 48728330 & c.264C > A & rs1597934612 & p.Tyr88Ter & $(4 \%)$ \\
Chr17: 48728053 & c.541C > T & rs1597933874 & p.Gln181Ter & $(4 \%)$ \\
Chr17: 48728042 & c.552C > A & rs1597933837 & p.Cys184Ter & $(4 \%)$ \\
Chr17: 48728010 & c.585G > A & rs867793282 & p.Trp195Ter & $(4 \%)$ \\
\hline
\end{tabular}

Table 2. Frequency (\%) of the European prostate cancer mutations HOXB13 G84E associated with the European-lineages haplogroups $\mathrm{R}$ of the among prostate cancer Moroccan males as in comparison with other reported studies.

\begin{tabular}{|c|c|c|c|c|c|c|c|}
\hline No & Population & $\begin{array}{c}\text { HOXB13 G84E } \\
(\%)\end{array}$ & $\begin{array}{c}\text { R1a1a-M17 } \\
(\%)\end{array}$ & $\begin{array}{c}\text { R1b1b2-M269 } \\
\text { (\%) }\end{array}$ & $\begin{array}{c}\text { E1b1b } \\
(\%)\end{array}$ & $\begin{array}{c}J \\
(\%)\end{array}$ & Reference \\
\hline 1 & Morocco & 0.0 & 0.0 & 0.0 & 55 & 35 & The present study \\
\hline 2 & Morocco & $\mathrm{NA}^{*}$ & 4.4 & 0.0 & 54.0 & 19.6 & Bekada et al. 2013 [43] \\
\hline 3 & British & 1.5 & 9.38 & 88.6 & 3.0 & 4.0 & $\begin{array}{c}\text { Helgason2000 [44] } \\
\text { Kote-Jarai et al. } 2015 \text { [7] } \\
\text { Wilson } 2001[32] \\
\text { Chen et al. } 2013[11]\end{array}$ \\
\hline 4 & Belgium & 3.85 & 4.0 & 63.04 & 2.0 & 5.0 & Rosser 2000 [45] Chen et al. 2013 [11] \\
\hline 5 & Dutch & 2.51 & 3.7 & 70.4 & 2.9 & 5.1 & Semino2000 [46] \\
\hline 6 & French & & 0.0 & 52.2 & 8.7 & 4.3 & Semino $2000[46]$ \\
\hline 7 & German & 0.49 & 16 & 50 & 6.2 & 4.0 & Semino 2000 [46] Chen et al. 2013 [11] \\
\hline 8 & Italian & & & 62.0 & 13.0 & 24.6 & Rootsi 2004 [33] \\
\hline 9 & Portuguese & & 2.0 & 62.0 & 11.0 & - & Rosser 2000 [45] \\
\hline 10 & Spanish & & 2.0 & 65.0 & 9.0 & 2.1 & Zalloua et al., 2008 [38] \\
\hline 11 & Swedes & 3.4 & 18 & 22.9 & 1.0 & 1.0 & Chen et al. 2013 [11] \\
\hline
\end{tabular}

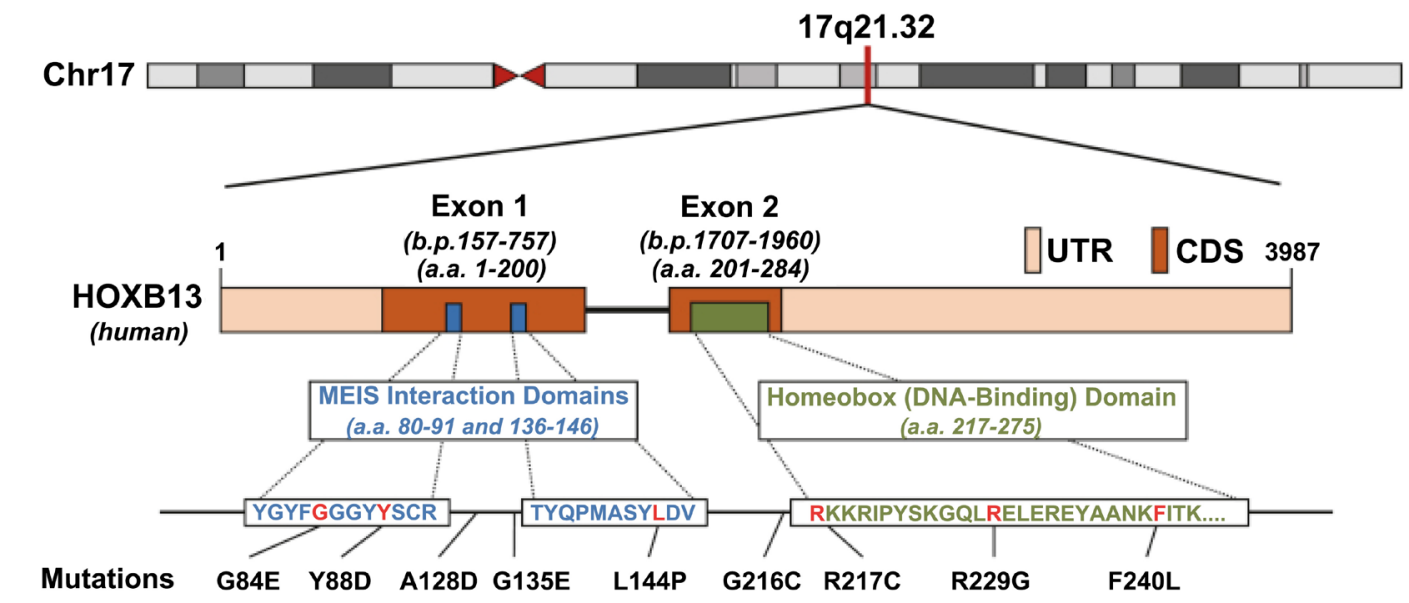

Figure 1. Genomic landscape of chromosome 17 shows the location of the HOXB13 gene (17q21.32) with genomic. 
G84E HOXB13 germline mutation $\mathrm{PCa}$ frequency rate \%

0.511 .522533 .544 .5

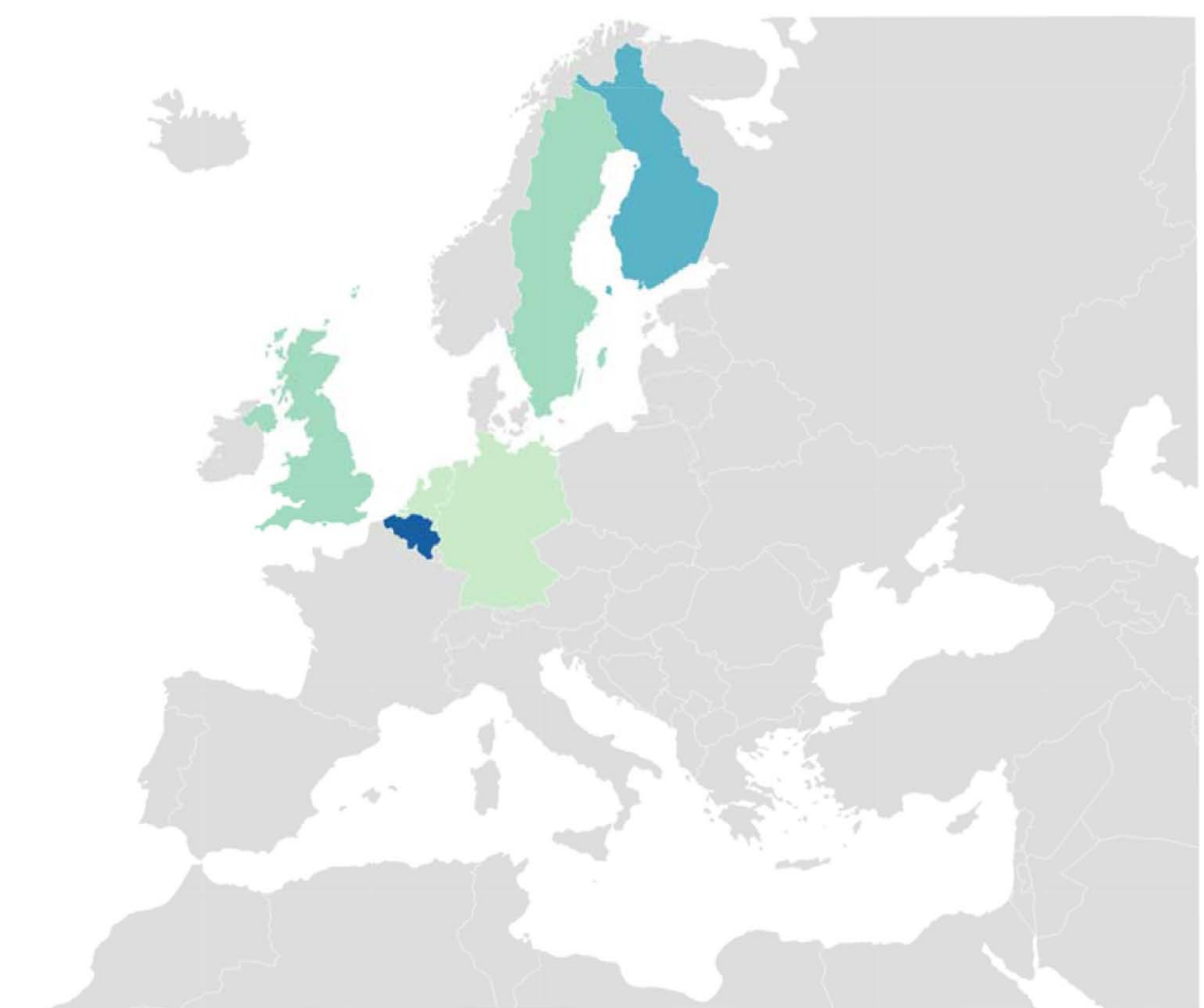

Greated with Datawrapper

Figure 2. Frequency (\%) of the prostate cancer mutations HOXB3 G24E among European PCa males.

R1a1a-M17) of the European ancestry and those of Moroccans (J and E1b1). The prevalence range for the Moroccan descent haplogroups were 35\% and 55\% for the J and E1b1 haplogroups, respectively. Conversely, there was total absence of the European lineage haplogroups R1a (0\%) and R1b (0\%) among Moroccans. Our results of the Y-chromosome were registered and deposited in the International Y-chromosome Haplotype Reference Database (YHRD) under the Accession Numbers YA003522 and YA003523 (http://www.yhrd.org/). For the rest of the $10 \%$ of the other haplogroups; which were outside the interest of the paper; ranged between $(0.8 \%-2.7 \%)$ and these were: $1.5 \%, 1.8 \%, 2.7 \%, 0.6 \%, 2.6 \%$ and $0.8 \%$ for the haplogroups $\mathrm{C}, \mathrm{G}, \mathrm{I}, \mathrm{L}, \mathrm{T}$, and $\mathrm{Q}$ respectively.

\section{Discussion}

In comparison with the PCa mutation reported to be associated with the European pedigree, all 5 identified SNP mutations of the HOXB13 gene ( $r s 1197613952$ (12\%), rs1597934612 (4\%), rs1597933874 (4\%), rs1597933837 (4\%) and rs867793282 (4\%)) among Moroccan PCa patients were completely new, and none of them 
had previously been reported in Europe as they are distinctively different from the HOXB13-G84E (rs138213197) SNP PCa mutation reported for the European genealogical lineages [10] [11] [12] [14] [22] [23] [24]. This shows evidently and conclusively the presence of allelic heterogeneity between the two adjacent population, and absence of any gene flow of the PCa G84E mutation from European population to Moroccans' gene pool. Moreover, comparison of the frequency of the genealogical lineages of the European Y-chromosome ancestry among Moroccans showed that both the Western European haplogroups R1b1b2-M269 and Eastern European haplogroups R1a1a-M17 [13] [25] [26] [27] were not detected among Moroccans. The synergistic absence of gene flow in the European HOXB13-G84E (rs138213197) PCa mutation on chromosome 17 and the haplogroups (R1b1b2-M269 and R1a1a-M17) of the Y-chromosome could be elucidated by limitations in intermarriage across the Mediterranean Sea between European and North African population; which can be attributed to many factors notably the obvious cultural barriers and practices, despite the historical continuous reciprocity migration and movements that occur between the limitrophe of Europe and North Africa. In comparison with other studies on gene flow, our findings were in consonance with the results of earlier studies that reported the presence of sharp discontinuity and limited gene flow between Northwestern Africa and Iberian Peninsula employing high-resolution analysis of the human Y-chromosome [28] [29]. Contrary, our results were in disagreement with the West-Eastern genetic cline reported on the differential admixture between Europe and North Africa neighboring population [30]. Since all identified mutation among PCa Moroccan patients were of the point-nonsense (stop codon) mutation type, the presupposition is that the change in the resultant proteins was due to the termination of translation earlier than anticipated. In this regard, the most common change in amino acid sequence was the change of tryptophan to tyrosine. The SNP mutation of PCa among Morrocans was associated with the J and E1b1 haplogroups of the Moroccan genealogical lineages of the Y-chromosome. It is anticipated that these results would help clinicians in Morocco not only to profile the PCa mutations but also to predict the prevalence of PCa heterogeneity among patients of European and Moroccan ancestry. These results can also be used globally to define criteria for prediagnosis vis-à-vis global comparative studies; Such as that gene flow of Y-chromosomal analysis of clan structure of Kalmyks, the only European Mongol people, and their relationship to Oirat-Mongols of Inner Asia [31] and other populations [32]-[42].

The prevalence of the SNP mutations among Moroccan PCa patients, which ranged from a minimum of $(4 \%)$ to a maximum of $(12 \%)$ was higher than that reported for European population [7] [10] [11] [42] particularly the unique SNP mutation, rs1197613952, which characterized the Moroccan PCa patients in terms of its high frequency (12\%) and position. These results represent a marked contrast to other circumstances in which the G84E mutation was reported to have the highest frequencies of $1.06 \%, 0.60 \%$ and $0.31 \%$ in Northern Europe, 
Western Europe and North America, respectively, as well as [11] and in Asian pastoral Nomadic population [25]. More recently, in a wide-ranging population sampling that included results from the UK Biobank, it was documented that the G84E mutation was found in 1545 (0.34\%) subjects out of 460,224 participants of European descent [15]. The observed high rate of frequency among Moroccan PCa patients was due to the high rate of consanguinity (40\%) among Moroccan population particularly the Bedouins [22]. Over centuries, this has led to more pathogenicity of these PCa mutations from one generation to another. The most prevalent mutation was the change in SNP of $(\mathrm{C}>\mathrm{A})$, which could be employed for prediction of PCa SNP mutations among Moroccan patients, and as a baseline study for any gene therapy innovative research in the future. This obviously will lead to better treatment and management outcomes worldwide.

The less frequent haplogroups C, G, I, L, T, and Q with frequency of $1.5 \%$, $1.8 \%, 2.7 \%, 0.6 \%, 2.6 \%$ and $0.8 \%$, respectively, were not included in the study design because we already knew that are minimal as reported by several thesis of our MSc students and they are irrelevant to both European as well as Moroccans genealogical lineages which we tested.

\section{Conclusion}

This study provides a new approach in deciphering the association between PCa mutation and the genealogical lineages of the Y-chromosome haplogroups. Our findings provide conclusive evidence that Moroccan PCa mutations show allelic heterogeneity with the European G84E mutations and therefore show absence of any gene flow of the PCa G84E mutation and the haplogroups (R1b1b2-M269 and R1a1a-M17) of Western and Eastern Europeans into Moroccans gene pool. These results have potential clinical applications on PCa profiling among different population ancestry, which could be inferred and predicted using its association with different genealogical lineages of the Y-chromosome haplogroups.

\section{Data Deposition and Availability}

All sequences of the determined mutation of the HOXB13 were deposited in NCBI GeneBank in accordance with each respective accession number, and have been made available on the public domain of the NCBI (http://www.ncbi.nlm.nih.gov/). Our results of the $\mathrm{Y}$-chromosome were registered and deposited in the International Y-chromosome Haplotype Reference Database (YHRD) under the Accession Numbers YA003522 and YA003523 (http://www.yhrd.org/).

\section{Acknowledgements}

The authors would like to appreciate the University of Sharjah, UAE, Al al-Bayt University, and Hassan II University of Casablanca, Morocco for providing the research facilities needed to accomplish this study. The authors would also like to thank NCBI GeneBank for registration of the determined sequences (http://www.ncbi.nlm.nih.gov/). 


\section{Funding}

None.

\section{Authors Contribution}

All authors shared equal contribution \& approved the final version.

\section{Conflicts of Interest}

The authors declare no conflicts of interest regarding the publication of this paper.

\section{References}

[1] Karlesson, R., Aly, M., Clements, M., Zheng, L., Adolfsson, J., Xu, J., Grönberg, H. and Wiklund, F. (2012) A Population-Based Assessment of Germline HOXB13 G84E Mutation and Prostate Cancer Risk. European Urology, 65, 169-176. https://doi.org/10.1016/j.eururo.2012.07.027

[2] Stott-Miller, M., Karyadi, D.M., Smith, T., Kwon, E.M., Kolb, S., Stanford, J.L., et al. (2013) HOXB13 Mutations in a Population-Based, Case-Control Study of Prostate Cancer. Prostate, 73, 634-641. https://doi.org/10.1002/pros.22604

[3] Laitinen, V.H., Wahlfors, T., Saaristo, L., Rantapero, T., Pelttari, L.M., Kilpivaara, O., et al. (2013) HOXB13 G84E Mutation in Finland: Population-Based Analysis of Prostate, breast, and Colorectal Cancer Risk. Cancer Epidemiol. Biomarkers Prev, 22, 452-460. https://doi.org/10.1158/1055-9965.EPI-12-1000-T

[4] Lin, X., Qu, L., Chen, Z., Xu, C., Ye, D., Shao, Q., et al. (2013) A Novel Germline Mutation in $H O X B 13$ Is Associated with Prostate Cancer Risk in Chinese Men. Prostate, 73, 169-175. https://doi.org/10.1002/pros.22552

[5] Xu, J., Lange, E.M., Lu, L., Zheng, S.L., Wang, Z., Thibodeau, S.N., et al. (2013) HOXB13 Is a Susceptibility Gene for Prostate Cancer: Results from the International Consortium for Prostate Cancer Genetics (ICPCG). Human Genetics, 132, 5-14. https://doi.org/10.1007/s00439-012-1229-4

[6] Kluźniak, W., Wokołorczyk, D., Kashyap, A., Jakubowska, A., Gronwald, J., Huzarski, T., et al. (2013) The G84E Mutation in the HOXB13 Gene Is Associated with an Increased Risk of Prostate Cancer in Poland. Prostate, 73, 542-548. https://doi.org/10.1002/pros.22594

[7] Kote-Jarai, Z., Mikropoulos, C., Leongamornlert, D.A., Dadaev, T., Tymrakiewicz, M., Saunders, E.J., et al. (2015) Prevalence of the HOXB13 G84E Germline Mutation in British Men and Correlation with Prostate Cancer Risk, Tumour Characteristics and Clinical Outcomes. Annals of Oncology, 26, 756-761. https://doi.org/10.1093/annonc/mdv004

[8] Ferlay, J., Soerjomataram, I., Dikshit, R., Eser, S., Mathers, C., Rebelo, M., et al. (2012) 2015. Cancer Incidence and Mortality Worldwide: Sources, Methods and Major Patterns in GLOBOCAN. International Journal of Cancer, 136, E359-E386. https://doi.org/10.1002/ijc.29210

[9] Mahasneh, I. (2018) Genetic Profiling of the 5-Top Cancers among Arabian Populations in Relation to Their Genealogical Landscape: Towards Establishment of Gene Therapy Platform in the Region. International Journal of Molecular Biology: Open Access, 3, 52-54. https://doi.org/10.15406/ijmboa.2018.03.00050

[10] Storebjerg, M., Høyer, S., Kirkegaard, P., Bro, F., The LuCamp Study Group, 
Ørntoft, T.F., Borre, M. and Sørensen, K.D. (2016) Prevalence of the HOXB13 G84E Mutation in Danish Men Undergoing Radical Prostatectomy and Its Correlations with Prostate Cancer Risk and Aggressiveness Tine. BJU International, 118, 646-653. https://doi.org/10.1111/bju.13416

[11] Chen, Z., Greenwood, C., Isaacs, W.B., Foulkes, W.D., Sun, J., Zheng, S.L., Condreay, L.D. and Xu, J. (2013) The G84E Mutation of HOXB13 Is Associated with Increased Risk for Prostate Cancer: Results from the Reduce Trial. Carcinogenesis, 34, 1260-1264. https://doi.org/10.1093/carcin/bgt055

[12] Maia, S., Cardoso, M., Pinto, P., Pinheiro, M., Santos, C., Peixoto, A., et al. (2015) Identification of Two Novel HOXB13 Germline Mutations in Portuguese Prostate Cancer Patients. PLOS ONE, 10, e0132728.

https://doi.org/10.1371/journal.pone.0132728

[13] Pinhasi. R., Thomas. M/G., Hofreiter, M., Currat, M. and Burger, J. (2012) The genetic history of Europeans. Trends in Genetics, 28, 496-505.

https://doi.org/10.1016/j.tig.2012.06.006

[14] Shang, Z., Zhu, S., Zhang, H., Li, L. and Niu, Y. (2013) Germline Homeobox B13 (HOXB13) G84E Mutation and Prostate Cancer Risk in European Descendants: A Meta-analysis of 24,213 Cases and 73,631 Controls. European Urology, 64, 173-176. https://doi.org/10.1016/j.eururo.2013.03.007

[15] Wei, J., Shi, Z., Na, R., Wang, C.-H., Kyle Resurreccion, W., Zheng, S.L., Hulick, P.J., Cooney, K.A., Helfand, B.T., Isaacs, W.B. and Xu, J. (2020) Germline HOXB13 G84E Mutation Carriers and Risk to Twenty Common Types of Cancer: Results from the UK Biobank. British Journal of Cancer, 123, 1356-1359. https://doi.org/10.1038/s41416-020-01036-8

[16] Bentayebi, K., Abada, F., Ihzmad, H. and Amzazi, S. (2014) Genetic Ancestry of a Moroccan Population as Inferred from Autosomal STRs. Meta Gene, 2, 427-438. https://doi.org/10.1016/j.mgene.2014.04.011

[17] Abumsimir, B., Mrabti, M., Laraqui, A., Ameur, A., Koraishi, S.I., Mzibrie M., Benchekroun M.N., Bessi H., Tiabi I., Mahasneh I. and Ennaji M.M. (2020) Most Frequent Mutational Events of Home Box 13 Gene in Prostatic Adenocarcinoma and Correlation with Tumor Characteristics. Meta Gene, 23, Article No. 100637. https://doi.org/10.1016/j.mgene.2019.100637

[18] Mahasneh, I., Abumsimir, B. and Ennaji, M.M. (2018) DNA Sequencing and Genotyping Profile of the Microsatellites of Y-STRs of the Beer-Alsabaa Bedouins of Jordan as Part of the Arabian Genome Project Since 1995. International Journal of Molecular Biology, 3, 151-154. https://doi.org/10.15406/ijmboa.2018.03.00067

[19] Mahasneh, I. and Hadi, S.M. (2008) STRs Analysis of Y-Chromosome among Arabian Population in Africa. MSc. Thesis, AL al-Bayt University, Al-Mafraq, 1-98.

[20] Mahasneh, I. and Ganyah, J. (2008) STRs Analysis of Y-Chromosome among Algerians. MSc. Thesis, AL al-Bayt University, Al-Mafraq, 1-124.

[21] Mahasneh, I.A. and Zuriegat, Q.H. (2019) Genetic Profiling of the Short Tandem Repeats (STRs) of Y-Chromosome of Populations of South Jordan. Journal of Forensic Medicine, 4, Article No. 127. http://www.hilarispublisher.com

[22] Brechka, H., Bhanvadia, R.R., Van Opstall, C. and Vander Griend, D.J. (2017) $H O X B 13$ Mutations and Binding Partners in Prostate Development and Cancer; Function, Clinical Significance, and Future Directions. Genes \& Diseases, 4, 75-87. https://doi.org/10.1016/j.gendis.2017.01.003

[23] Akbari, M.R., Trachtenberg, J., Lee, J., Tam, S., Bristow, R., Loblaw, A., et al. (2012) Association between Germline HOXB13 G84E Mutation and Risk of Prostate Can- 
cer. Journal of the National Cancer Institute, 104, 1260-1262.

https://doi.org/10.1093/jnci/djs288

[24] Ewing, C.M., Ray, A.M., Lange, E.M., Zuhlke, K.A., Robbins, C.M., Tembe, W.D., et al. (2012) Germline Mutations in HOXB13 and Prostate Cancer Risk. New England Journal of Medicine, 366, 141-149. https://doi.org/10.1056/NEJMoa1110000

[25] Balaresque, P., Poulet, N., Cussat-Blanc, S., Gerard, P., Quintana-Murci, L., Heyer, E. and Jobling, M.A. (2015) Y-Chromosome Descent Clusters and Male Differential Reproductive Success: Young Lineage Expansions Dominate Asian Pastoral Nomadic Population. European Journal of Human Genetics, 23, 1413-1422. https://doi.org/10.1038/ejhg.2014.285

[26] Underhill, P.A., Shen, P., Lin, A.A., Jin, L., Passarino, G., Yang, W.H., et al. (2000) Y-Chromosome Sequence Variation and the History of Human Population. Nature Genetics, 26, 358-361. https://doi.org/10.1038/81685

[27] Robert, M. (2012) Germanic Origins from the Perspective of the Y-Chromosome. PhD Thesis. University of Berkeley, California, $180 \mathrm{p}$. https://escholarship.org/uc/item/9v44n49p.

[28] Bosch, E., Calafell, F., Comas, D., Oefner, P.J., Underhill, P. and Bertranpetit, J. (2001) High-Resolution Analysis of Human Y-Chromosome Variation Shows a Sharp Discontinuity and Limited Gene Flow between Northwestern Africa and the Iberian Peninsula. The American Journal of Human Genetics, 68, 1019-1029. https://doi.org/10.1086/319521

[29] Gleize, Y., Mendisco, F., Pemonge, M.-H., Hubert, C., Groppi, A., Houix, B., et al. (2016) Early Medieval Muslim Graves in France: First Archaeological, Anthropological and Palaeogenomic Evidence. PLoS ONE, 11, e0148583. https://doi.org/10.1371/journal.pone.0148583

[30] Serra-Vidal, G., Lucas-Sanchez, M., Fadhlaoui-Zid, K., Asmahan, B., Zalloua, P. and Comas, D. (2019) Heterogeneity in Palaeolithic Population Continuity and Neolithic Expansion in North Africa. Current Biology, 29, 3953-3959.E4. https://doi.org/10.1016/j.cub.2019.09.050

[31] Balinova, N., Post, H., Kushniarevich, A., Flores, R., Karmin, M., Sahakyan, H., et al. (2019) Y-Chromosomal Analysis of Clan Structure of Kalmyks, the Only European Mongol People, and Their Relationship to Oirat-Mongols of Inner Asia. European Journal of Human Genetics, 9, 1466-1474. https://doi.org/10.1038/s41431-019-0399-0

[32] Wilson, J.F., Weiss, D.A., Richards, M., Thomas, M.G., Bradman, N. and Goldstein, D.B. (2001) Genetic Evidence for Different Male and Female Roles during Cultural Transitions in the British Isles. Proceedings of the National Academy of Sciences of the United States of America, 98, 5078-5083. https://doi.org/10.1073/pnas.071036898

[33] Rootsi, S. (2004) Human Y-Chromosomal Variation in European Populations. PhD Thesis, Tartu University Press, Tartu, hdl: 10062/1252.

[34] Abumsimir, B.O. (2010) Genetic Homogeneity of Y-Chromosome STRs among Beer Alsabaa Bedouin in Zarqa District/Jordan. MSc. Thesis, Al al-Bayt University, Al-Mafraq.

[35] Arredi, B., Poloni, E.S., Paracchini, S., Zerjal, T., Fathallah, D.M., Makrelouf, M., et al. (2004) A Predominantly Neolithic Origin for Y-Chromosomal DNA Variation in North Africa. The American Journal of Human Genetics, 75, 338-345. https://doi.org/10.1086/423147

[36] Breyer, J.P., Avritt, T.G., McReynolds, K.M., Dupont, W.D. and Smith, J.R. (2012) 
Confirmation of the HOXB13 G84E Germline Mutation in Familial Prostate Cancer. Cancer Epidemiology, Biomarkers \& Prevention, 21, 1348-1353.

https://doi.org/10.1158/1055-9965.EPI-12-0495

[37] Cruciani, F., La Fratta, R., Santolamazza, P., Sellitto, D., Pascone, R., Moral, P., et al. (2004) Phylogeographic Analysis of Haplogroup E3b (E-M215) Y-Chromosome Reveals Multiple Migratory Events within and outside Africa. The American Journal of Human Genetics, 74, 1014-1022. https://doi.org/10.1086/386294

[38] Zalloua, P.A., Platt, D.E., El Sibai, M., Khalife, J., Makhoul, N., Haber, M., Xue, Y., et al. (2008) Identifying Genetic Traces of Historical Expansions: Phoenician Footprints in the Mediterranean. The American Journal of Human Genetics, 83, 633-642. https://doi.org/10.1016/j.ajhg.2008.10.012

[39] Rajab, B.A.M. (2008) STRs Analysis of Y-Chromosome among the Arabian Gulf Countries, Syria and Lebanon. MSc. Thesis, AL al-Bayt University, Al-Mafraq, 1-124.

[40] Onofri, V., Alessandrini, F., Turchi, C., Pesaresi, M. and Tagliabracci, A. (2008) Y-Chromosome Markers Distribution in Northern Africa: High-Resolution SNP and STR Analysis in Tunisia and Morocco Populations. Forensic Science International: Genetics Supplement Series, 1, 235-236.

https://doi.org/10.1016/j.fsigss.2007.10.173

[41] Semino, O., Magri, C., Benuzzi, G., Lin, A.A., Al-Zahery, N., Battaglia, V., et al. (2004) Origin, Diffusion, and Differentiation of Y-Chromosome Haplogroups E and J: Inferences on the Neolithization of Europe and Later Migratory Events in the Mediterranean Area. The American Journal of Human Genetics, 74, 1023-1034. https://doi.org/10.1086/386295

[42] Zeltser, L., Desplan, C. and Heintz, N. (1996) HOXB-13: A New Hox Gene in a Distant Region of the $H O X B$ Cluster Maintains Colinearity. Development, 122, 2475-2484. https://doi.org/10.1242/dev.122.8.2475

[43] Bekada, A., Fregel, R., Cabrera, V.M., Larruga, J.M., Pestano, J., Benhamamouch, S. and González, A.M. (2013) Introducing the Algerian Mitochondrial DNA and Y-Chromosome Profiles into the North African Landscape. PLoS ONE, 8, e56775. https://doi.org/10.1371/journal.pone.0056775

[44] Helgason, A., Sigurðardóttir, S., Nicholson, J., Sykes, B., Hill, E.W., Bradley, D.G., et al. (2000) Estimating Scandinavian and Gaelic Ancestry in the Male Settlers of Iceland. American Journal of Human Genetics, 67, 697-717. https://doi.org/10.1086/303046

[45] Rosser, Z.H., Zerjal, T., Hurles, M.E., Adojaan, M., Alavantic, D., Amorim, A., et al. (2000) Y-Chromosomal Diversity in Europe Is Clinal and Influenced Primarily by Geography, Rather than Language. American Journal of Human Genetics, 67, 1526-1543. https://doi.org/10.1086/316890

[46] Semino, O., Passarino, G., Oefner, P.J., Lin, A.A., Arbuzova, S., Beckman, L.E., et al. (2000) The Genetic Legacy of Paleolithic Homo sapiens in Extant Europeans: A Y-Chromosome Perspective. Science, 290, 1155-1159. https://doi.org/10.1126/science.290.5494.1155 